Research Article

\title{
Investigation on the Sulfuric Acid Corrosion Mechanism for Concrete in Soaking Environment
}

\author{
Hongguang Min $\mathbb{D D}^{1,2,3}$ and Zhigang Song $\mathbb{D}^{3}$ \\ ${ }^{1}$ Guangdong Provincial Key Laboratory of Durability for Marine Civil Engineering, College of Civil Engineering, \\ Shenzhen University, 3688 Nanhai Avenue, Shenzhen 518060, China \\ ${ }^{2}$ Shenzhen Graduate School, Harbin Institute of Technology, Shenzhen 518055, China \\ ${ }^{3}$ Faculty of Civil Engineering and Mechanics, Kunming University of Science and Technology, 727 South Jingming Road, \\ Kunming 650500, China
}

Correspondence should be addressed to Hongguang Min; minhongguang@163.com

Received 23 January 2018; Accepted 31 March 2018; Published 7 May 2018

Academic Editor: Estokova Adriana

Copyright ( 2018 Hongguang Min and Zhigang Song. This is an open access article distributed under the Creative Commons Attribution License, which permits unrestricted use, distribution, and reproduction in any medium, provided the original work is properly cited.

\begin{abstract}
This paper chooses the apparent diffusion coefficient for $\mathrm{OH}^{-}$(hydroxyl ion) for concrete as an index to evaluate the corrosion degree of concrete subjected to sulfuric acid. Based on the reaction boundary layer theory, a sulfuric acid corrosion model for concrete was established and verified through experiments. The experiment design and data processing of sulfuric acid corrosion tests for concrete were carried out using uniform test design and nonparametric regression. Effects of water-cement ratio and $\mathrm{pH}$ value are presented on the sulfuric acid corrosion mechanism for concrete. Test results show that when the $\mathrm{pH}$ value was 2.50 , the sulfuric acid corrosion degree of concrete was the most serious. The boundary layer effect always existed in the sulfuric acid corrosion for concrete, and the corrosion process included rapid and stable corrosion stages. The apparent diffusion coefficient for $\mathrm{OH}^{-}$for concrete increased with the decrease of $\mathrm{pH}$ value and the increase of water-cement ratio and cement proportion.
\end{abstract}

\section{Introduction}

Aggressive sulfuric acid is mainly derived from acid rain, industrial environment, and sewage treatment systems [1-4]; further, the physical and chemical reactions between aggressive sulfuric acid and cement hydration products are primary reasons for durability failure of concrete structures [5]. For example, the $\mathrm{pH}$ value of inner concrete decreases in a sulfuric acid corrosion environment, which leads to the destruction of the passive film on the surface of reinforcement steel bars, followed by severe steel bar corrosion. Previous studies have shown that water-cement ratio, $\mathrm{pH}$ value, type and proportion of cement, coarse aggregate content, mineral admixture, and other factors have important effects on the sulfuric acid corrosion mechanism for concrete [6-13]. In fact, these factors will affect the pore structures of concrete, and the change of pore structures will significantly affect the transport performance of concrete
[14-17], which results in a decline in concrete resistance to sulfuric acid corrosion. Being different from the mechanism of sulfate attack on concrete $[11,12,18,19]$, the sulfuric acid corrosion mechanism for concrete is the result of a combined action of dissolved corrosion caused by hydrogen ion $\left(\mathrm{H}^{+}\right)$and expanded corrosion caused by $\mathrm{SO}_{4}{ }^{2-}$ (sulfate ion) [20]. This finding led Böhm et al. [21] to propose a moving boundary diffusion model, which can be used to predict sulfide corrosion rate for concrete. Böhm et al. [21] also studied the influencing factors of sulfuric acid corrosion rate. Based on this, Böhm et al. [22] and Jahani et al. [23] predicted sulfuric acid corrosion rate and corrosion layer thickness for concrete and cement mortar through applying the moving boundary diffusion model [21], which were also verified by experiments. Overall, the sulfuric acid corrosion mechanism for concrete is complicated. This mechanism has been studied by different researchers from different aspects; however, differences between these research results still 
exist. Therefore, the prediction model for concrete corrosion due to sulfuric acid needs to be further studied.

Based on the theory of reaction boundary layer, this paper presents a sulfuric acid corrosion model for concrete combined with the authors' previous research results [24]. Thus, the apparent diffusion coefficient of $\mathrm{OH}^{-}$(hydroxyl ion) for concrete was analyzed, and the corresponding theoretical formula was also put forward. Long-term soaking tests for concrete subjected to sulfuric acid corrosion were carried out for 150 days through applying uniform design and nonparametric regression. This study's observations on the effects of water-cement ratio and $\mathrm{pH}$ value on concrete sulfuric acid corrosion mechanism led to an apparent diffusion coefficient for $\mathrm{OH}^{-}$for concrete. At length, the sulfuric acid corrosion model for concrete was verified by experiments.

\section{Sulfuric Acid Corrosion Model for Concrete}

$\mathrm{Ca}(\mathrm{OH})_{2}$ (calcium hydroxide) in concrete dissolves in water to form the saturated $\mathrm{Ca}(\mathrm{OH})_{2}$ solution, which produces $\mathrm{Ca}^{2+}$ (calcium ion) and $\mathrm{OH}^{-}$by ionization. Because of the existence of concentration gradient, $\mathrm{Ca}^{2+}$ and $\mathrm{OH}^{-}$diffuse into the soaking solution through the corrosion layer from the inner concrete. However, $\mathrm{H}^{+}$(hydrogen ion) and $\mathrm{SO}_{4}{ }^{2-}$ diffuse into the inner concrete through the corrosion layer from the soaking solution under the action of concentration gradient thereby forming the reaction boundary layer. On the outer boundary of the reaction boundary layer, the $\mathrm{OH}^{-}$ concentration is zero, and the $\mathrm{H}^{+}$concentration is the concentration of the soaking solution $\mathrm{H}^{+}$; however, on the inner boundary of the noncorrosion surface, the $\mathrm{H}^{+}$concentration is zero, and the $\mathrm{OH}^{-}$concentration is the concentration found in the saturated $\mathrm{Ca}(\mathrm{OH})_{2}$ solution. The sulfuric acid corrosion for concrete occurs in the reaction boundary layer, as shown in Figure 1.

In the process of sulfuric acid corrosion for concrete, $\mathrm{OH}^{-}$diffuses from interior to exterior of concrete under the action of concentration gradient and reacts with $\mathrm{H}^{+}$in the soaking solution to form the reaction boundary layer. Only when the $\mathrm{OH}^{-}$of the concrete surface has been consumed by $\mathrm{H}^{+}$in the soaking solution, the excess of $\mathrm{H}^{+}$continue to spread to the inner concrete in the concentration gradient effect and further react with $\mathrm{OH}^{-}$inner concrete. Therefore, the whole process of sulfuric acid corrosion relies on the dissolution of $\mathrm{Ca}(\mathrm{OH})_{2}$ out of concrete and consumption by $\mathrm{H}^{+}$in the soaking solution.

Sulfuric acid corrosion for concrete belongs to strong acid corrosion. Sulfuric acid reacts with $\mathrm{Ca}(\mathrm{OH})_{2}$ in concrete, and the dissolution of generated soluble calcium salts causes the reaction process to continue and the alkalinity of concrete to decrease. Reactions occurring in the reaction boundary layer formed by the sulfuric acid corrosion for concrete can be represented as

$$
\mathrm{Ca}^{2+}+2 \mathrm{OH}^{-}+2 \mathrm{H}^{+}+\mathrm{SO}_{4}^{2-}=\mathrm{CaSO}_{4}+2 \mathrm{H}_{2} \mathrm{O} \text {. }
$$

According to (1), the mole ratio of $\mathrm{OH}^{-}$and $\mathrm{H}^{+}$is $1: 1$ in the reaction process, so the apparent diffusion coefficient for concrete is considered to be a constant. Assuming that the concentration change of $\mathrm{OH}^{-}$in the reaction boundary

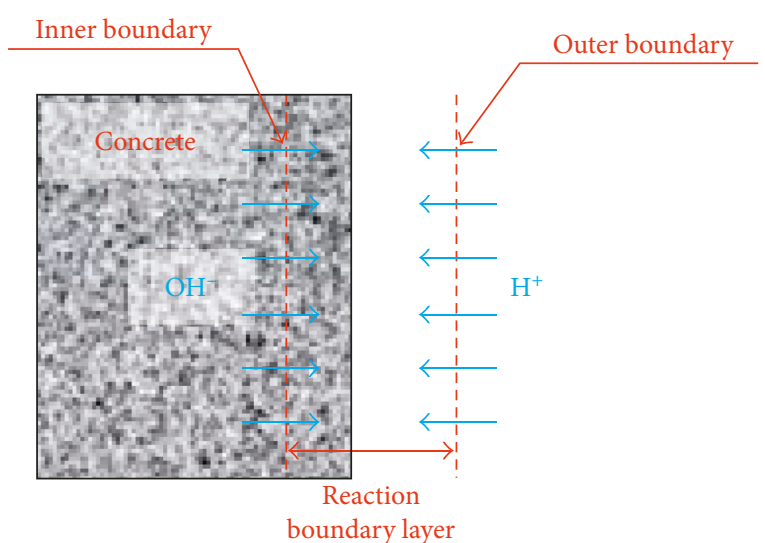

FIGURE 1: Reaction boundary layer of sulfuric acid corrosion on concrete.

layer is consistent with the diffusion process of homogeneous reaction; then the whole diffusion process can be expressed as

$$
\begin{aligned}
\frac{\partial C_{\mathrm{OH}^{-}}(x, t)}{\partial t}= & D_{\mathrm{OH}^{-}} \cdot \frac{\partial^{2} C_{\mathrm{OH}^{-}}(x, t)}{\partial x^{2}} \\
& -k \cdot C_{\mathrm{OH}^{-}}(x, t) \cdot C_{\mathrm{H}^{+}}(x, t),
\end{aligned}
$$

where $x$ is the distance of a point within the reaction boundary layer from the inner boundary $(\mathrm{m})$, and $t$ is the soaking time $(s) . k$ is the reaction rate constant for $\mathrm{OH}^{-}$and $\mathrm{H}^{+}\left(\mathrm{L} \cdot \mathrm{mol}^{-1} \cdot \mathrm{s}^{-1}\right)$. Meanwhile, $C_{\mathrm{OH}^{-}}(x, t)$ and $C_{\mathrm{H}^{+}}(x, t)$ are the concentrations of $\mathrm{OH}^{-}$and $\mathrm{H}^{+}$at location $x$ and time $t$ $\left(\mathrm{mol} \cdot \mathrm{L}^{-1}\right)$, respectively. $D_{\mathrm{OH}^{-}}$is the apparent diffusion coefficient for $\mathrm{OH}^{-}$for concrete $\left(\mathrm{m}^{2} \cdot \mathrm{s}^{-1}\right)$.

Equation (3) gives the boundary conditions of (2) as

$$
\begin{aligned}
C_{\mathrm{OH}^{-}}(0, t) & =C_{\mathrm{OH}^{-}} ; C_{\mathrm{OH}^{-}}(\delta, t)=0, \\
C_{\mathrm{H}^{+}}(\delta, t) & =C_{\mathrm{H}^{+}} ; C_{\mathrm{H}^{+}}(0, t)=0,
\end{aligned}
$$

where $\mathrm{C}_{\mathrm{OH}^{-}}$is the concentration of $\mathrm{OH}^{-}$in the saturated $\mathrm{Ca}$ $(\mathrm{OH})_{2}$ solution $\left(\mathrm{mol} \cdot \mathrm{L}^{-1}\right), \mathrm{C}_{\mathrm{H}^{+}}$is the concentration of $\mathrm{H}^{+}$in the soaking solution (mol. $\mathrm{L}^{-1}$ ), and $\delta$ is the thickness of the reaction boundary layer $(\mathrm{m})$.

Assuming that concentration distributions in the reaction boundary layer for $\mathrm{OH}^{-}$and $\mathrm{H}^{+}$are satisfied, the following functions are derived as

$$
\begin{array}{r}
C_{\mathrm{OH}^{-}}(x, t)=C_{\mathrm{OH}^{-}} \cdot \varphi(\theta) ; C_{\mathrm{H}^{+}}(x, t)=C_{\mathrm{H}^{+}} \cdot \psi(\theta), \\
\theta=\delta(t) ; \delta(0)=0,
\end{array}
$$

where $\varphi(\theta)$ and $\psi(\theta)$ are the shape functions of concentration distributions in the reaction boundary layer for $\mathrm{OH}^{-}$ and $\mathrm{H}^{+}$, respectively. $\delta(t)$ is the thickness function of the reaction boundary layer.

Equations (3) and (4) show that $\varphi(\theta)$ and $\psi(\theta)$ must satisfy the following conditions as

$$
\begin{aligned}
& \varphi(0)=1 ; \varphi(1)=0 ; \varphi^{\prime}(1)=0, \\
& \psi(0)=0 ; \psi(1)=1 ; \psi^{\prime}(0)=0 .
\end{aligned}
$$

When combined with (2) and (4), the result can be shown as 


$$
\delta^{-1}(t) \cdot \int_{0}^{1}-\theta \cdot \varphi^{\prime}(\theta) \cdot d \theta \cdot \frac{d \delta(t)}{d t}=D_{\mathrm{OH}^{-}} \cdot \delta^{-2}(t) \cdot \int_{0}^{1} \varphi^{\prime \prime}(\theta) \cdot d \theta-k \cdot C_{\mathrm{H}^{+}} \cdot \int_{0}^{1} \varphi(\theta) \cdot \psi(\theta) \cdot d \theta
$$

which allows solving (6) as

$$
\begin{aligned}
\delta^{2}(t)= & N \cdot D_{\mathrm{OH}^{-}} \cdot\left(k \cdot P \cdot C_{\mathrm{H}^{+}}\right)^{-1} \\
& \cdot\left[1-\exp \left(-2 k \cdot P \cdot C_{\mathrm{H}^{+}} \cdot M^{-1} \cdot t\right)\right], \\
M= & \int_{0}^{1}-\theta \cdot \varphi^{\prime}(\theta) \cdot d \theta, \\
N= & \int_{0}^{1} \varphi^{\prime \prime}(\theta) \cdot d \theta=\left.\varphi^{\prime}(\theta)\right|_{0} ^{1}=\varphi^{\prime}(1)-\varphi^{\prime}(0)=-\varphi^{\prime}(0), \\
P= & \int_{0}^{1} \varphi(\theta) \cdot \psi(\theta) \cdot d \theta .
\end{aligned}
$$

On the inner boundary within the reaction boundary layer, the relationship between the acid consumption rate of concrete and time can be expressed as

$$
\begin{aligned}
v_{\mathrm{H}^{+}}(t) & =-\left.S \cdot D_{\mathrm{OH}^{-}} \cdot \frac{\partial C_{\mathrm{OH}^{-}}(x, t)}{\partial x}\right|_{x=0} \\
& =-S \cdot D_{\mathrm{OH}^{-}} \cdot C_{\mathrm{OH}^{-}} \cdot \varphi^{\prime}(0) \cdot \delta^{-1}(t),
\end{aligned}
$$

where $S$ is the area of soaking surface $\left(\mathrm{m}^{2}\right)$, and $v_{\mathrm{H}^{+}}(t)$ is the acid consumption rate of concrete, that is, $\mathrm{H}^{+}$consumption per unit time $\left(\mathrm{mol} \cdot \mathrm{s}^{-1}\right)$.

$$
\begin{aligned}
& \text { Substituting (7) into (8) gives } \\
& \begin{aligned}
v_{\mathrm{H}^{+}}(t) & =A \cdot[1-\exp (-B \cdot t)]^{-1 / 2} \\
A & =S \cdot C_{\mathrm{OH}^{-}} \cdot\left(k \cdot N \cdot P \cdot D_{\mathrm{OH}^{-}} \cdot C_{\mathrm{H}^{+}}\right)^{1 / 2} \\
B & =2 k \cdot P \cdot C_{\mathrm{H}^{+}} \cdot M^{-1} .
\end{aligned}
\end{aligned}
$$

Equation (9) shows that the acid consumption rate of concrete is relatively high in the initial reaction stage, decreases rapidly with the increase of reaction time, and will eventually become a constant, $A$. Hence, the whole process consists of two stages, that is, decline and stability. Then, the experimental study and theoretical analysis for concrete subjected to sulfuric acid corrosion can be carried as shown in Section 3 .

\section{Materials and Methods}

3.1. Experimental Design and Specimen Preparation. The uniform test design method $[25,26]$ is a test design method that only considers the "uniform dispersion" of the test point in the test range. It is designed by the well-designed tables: the uniform design table. The uniform design table is usually represented by $U_{n}\left(q^{s}\right)$, where $U$ means uniform design, $n$ means $n$ tests, $q$ indicates that every factor has $q$ levels, and $s$ indicates that the table has s columns, for example, $U_{8}\left(8^{5}\right)$, which means that 8 tests are required, each factor has 8 levels, the table has 5 columns, and a maximum of 5 factors. The biggest characteristic of uniform test design is that the number of tests required is usually equal to the level number of factors. When the test factors have the same level number, the uniform test design needs less tests than the orthogonal test design.
Considering the effects of the two factors of water-cement ratio and soaking solution's $\mathrm{pH}$ value on the sulfuric acid corrosion mechanism for concrete, both factors have eight levels (Table 1). Because this test is a problem of two factors and eight levels, enabling better test results with fewer test numbers, sulfuric acid corrosion tests for concrete were designed according to the uniform test design method, as shown in Table 2. Twenty-four concrete specimens were cast. The sizes were all $100 \mathrm{~mm} \times 100 \mathrm{~mm} \times 100 \mathrm{~mm}$, and each kind of watercement ratio consisted of three specimens. The continuous graded gravel of 5-16 mm was used as the coarse aggregate. The concrete mix proportions are in Table 3. Concrete specimens were taken out from the standard curing room after 28 days.

3.2. Sulfuric Acid Corrosion Tests for Concrete. Five surfaces of concrete specimens were sealed with paraffin, leaving only one surface as the exposed surface. Eight plastic boxes were used as the soaking pool, and three concrete specimens were placed into each soaking pool. In addition, the exposed surface of each concrete specimen was completely perpendicular to the bottom of the soaking pool. These specimens remained in their boxes and soaking for 150 days at room temperature, as shown in Figure 2.

The soaking solutions of sulfuric acid were prepared with different initial $\mathrm{pH}$ values by mixing the distilled water and concentrated sulfuric acid, and the volume of soaking solution of each group was always $10 \mathrm{~L}$. The change of soaking solution's $\mathrm{pH}$ was measured by a portable $\mathrm{pH}$ meter in time, and then the soaking solution was titrated with sulfuric acid in time by a rubber head dropper and a cylinder so as to ensure the soaking solution's $\mathrm{pH}$ value was basically constant. At the same time, the liquid phase was stirred to ensure a uniform concentration of sulfuric acid throughout the volume of the liquid phase.

In the early stage of experiment, the soaking solution was titrated with sulfuric acid when the measured $\mathrm{pH}$ value was up to the titration $\mathrm{pH}$ value; however, in the final stage of experiment, even if the measured $\mathrm{pH}$ value was not up to the titration $\mathrm{pH}$ value, the soaking solution was still titrated with sulfuric acid to the initial $\mathrm{pH}$ value. Table 4 shows the titration $\mathrm{pH}$ value and titration sulfuric acid concentration. During the titration process, each titration time was recorded along with the amount of titration sulfuric acid, and the average acid consumption rate was obtained by dividing the amount of titration sulfuric acid at each interval based on the consecutive titration time periods.

\section{Results and Discussion}

4.1. Apparent Characteristics of Concrete Subjected to Sulfuric Acid Corrosion. After 150 days, the concrete specimens subjected to sulfuric acid corrosion were taken out with different water-cement ratios in the soaking solutions of different $\mathrm{pH}$ values. Figure 3 shows the apparent changes in 
TABLE 1: Water-cement ratio and soaking solution's $\mathrm{pH}$ value.

\begin{tabular}{lcccccccc}
\hline \multirow{2}{*}{ Parameter } & \multicolumn{9}{c}{ Level number } \\
& 1 & 2 & 3 & 4 & 5 & 6 & 7 \\
\hline Water-cement ratio & 0.70 & 0.65 & 0.60 & 0.55 & 0.50 & 0.45 & 0.40 \\
pH value & 4.00 & 3.70 & 3.40 & 3.10 & 2.80 & 2.50 & 2.20 & 2.00 \\
\hline
\end{tabular}

TABLE 2: Uniform test design.

\begin{tabular}{lcccccccc}
\hline \multirow{2}{*}{ Parameter } & \multicolumn{9}{c}{ Test number } & \multicolumn{3}{c}{6} & 7 \\
& 1 & 2 & 3 & 4 & 5 & 0.50 & 0.45 & 0.40 \\
Water-cement ratio & 0.70 & 0.65 & 0.60 & 0.55 & 0.35 \\
pH value & 3.10 & 2.00 & 3.40 & 2.20 & 3.70 & 2.50 & 4.00 & 2.80 \\
\hline
\end{tabular}

TABle 3: Concrete mix proportions design $\left(\mathrm{kg} \cdot \mathrm{m}^{-3}\right)$.

\begin{tabular}{|c|c|c|c|c|c|c|c|c|c|}
\hline \multirow{2}{*}{ Material } & \multirow{2}{*}{ Type } & \multicolumn{8}{|c|}{ Water-cement ratio $(w / c)$} \\
\hline & & 0.70 & 0.65 & 0.60 & 0.55 & 0.50 & 0.45 & 0.40 & 0.35 \\
\hline Water $(w)$ & Tap water & 210 & 210 & 210 & 210 & 210 & 210 & 215 & 168 \\
\hline Cement $(c)$ & $\# 425 \mathrm{OPC}^{1}$ & 300 & 323 & 350 & 382 & 420 & 467 & 538 & 480 \\
\hline Fine aggregate (FA) & Artificial sand & 765 & 739 & 676 & 665 & 618 & 586 & 528 & 532 \\
\hline Coarse aggregate (CA) & Gravel & 1057 & 1063 & 1103 & 1085 & 1098 & 1089 & 1071 & 1131 \\
\hline
\end{tabular}

${ }^{1} \mathrm{OPC}$ represents ordinary Portland cement.

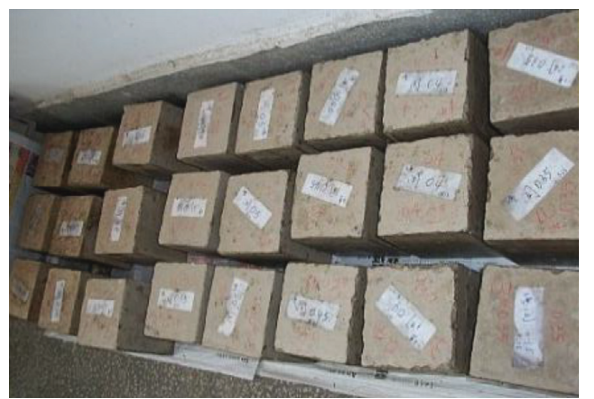

(a)

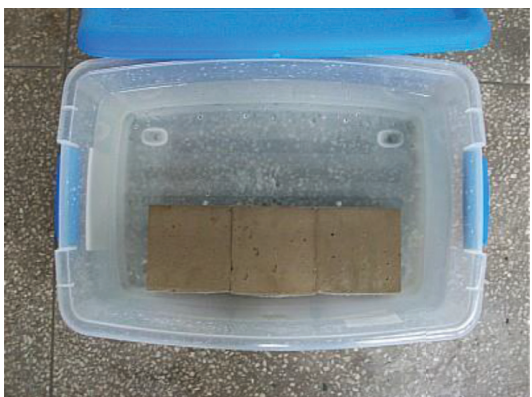

(b)

FIGURE 2: Test layout for sulfuric acid corrosion on concrete: (a) specimens and (b) soaking pool.

the characteristics of concrete specimens. With the decrease of $\mathrm{pH}$ value, the color of each exposed surface of concrete specimen in turn was gray, yellow, and white. The gray surface indicated that the corrosion degree of the concrete specimen suffered sulfuric acid was light, and the color of the exposed surface was basically the same as the noncorrosion surface. The yellow surface revealed that the sulfuric acid corrosion degree was serious, and the surface of the concrete specimen had a loose yellow sand layer. The white surface shows that a large amount of $\mathrm{CaSO}_{4}$ (calcium sulfate) was deposited on the concrete specimen surface. In the initial stage of the sulfuric acid corrosion of concrete, the reaction rate was very fast and a large amount of $\mathrm{CaSO}_{4}$ was produced. At the same time, $\mathrm{CaSO}_{4}$ blocked the surface pores of concrete specimen, which caused the corrosion reaction rate to gradually slow down, so the corrosion degree gradually decreased.

The sizes of concrete specimens were measured before and after sulfuric acid corrosion using a vernier caliper.
These concrete specimen measurements of the average corrosion layer thicknesses' exposure to sulfuric acid after 150 days are shown in Figure 4. When the soaking solution's $\mathrm{pH}$ value was 2.50 , the corrosion layer thickness was the largest, and the sulfuric acid corrosion degree was the most serious. When the soaking solution's $\mathrm{pH}$ value was between 2.50 and 4.00 , with the decrease of $\mathrm{pH}$ value, the corrosion layer thickness increased, and the sulfuric acid corrosion degree became more and more serious. This may be because in the process of sulfuric acid corrosion for concrete, the formation rate of $\mathrm{CaSO}_{4}$ was not much different from the dissolution rate, so the corrosion reaction continued into the concrete interior. However, the corrosion layer thickness decreased with the decrease of $\mathrm{pH}$ value when the soaking solution's $\mathrm{pH}$ value was between 2.00 and 2.50 , leading to a progressively smaller sulfuric acid corrosion degree. This may be because the formation rate of $\mathrm{CaSO}_{4}$ in the early corrosion reaction was far greater than its dissolution rate, 
TABLE 4: Titration $\mathrm{pH}$ value and titration sulfuric acid concentration.

\begin{tabular}{lcccccccc}
\hline Test group & 1 & 2 & 3 & 4 & 5 & 6 & 7 & 8 \\
\hline Water-cement ratio & 0.40 & 0.50 & 0.60 & 0.70 & 0.35 & 0.45 & 0.55 & 0.65 \\
Initial pH value & 4.00 & 3.70 & 3.40 & 3.10 & 2.80 & 2.50 & 2.20 & 2.00 \\
Titration pH value & 5.00 & 4.00 & 3.60 & 3.30 & 3.00 & 2.70 & 2.30 & 2.10 \\
Titration sulfuric acid concentration $\left(\mathrm{mol} \cdot \mathrm{L}^{-1}\right)$ & 0.125 & 0.125 & 0.125 & 0.125 & 0.125 & 0.500 & 0.500 & 0.500 \\
\hline
\end{tabular}

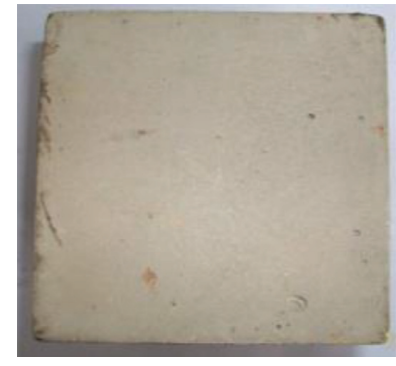

(a)

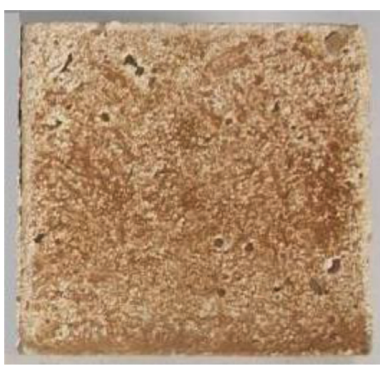

(e)

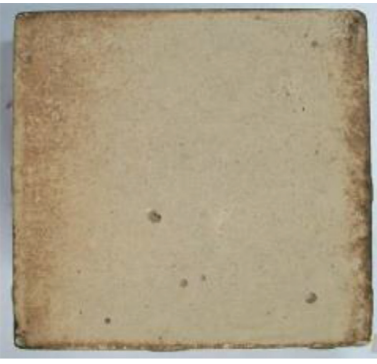

(b)

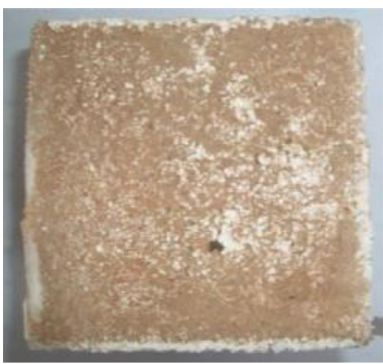

(f)

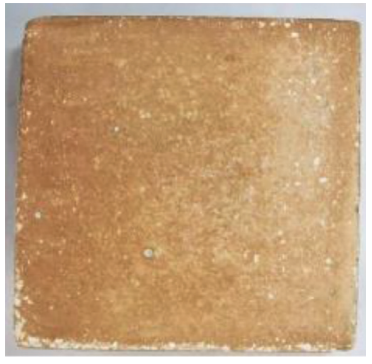

(c)

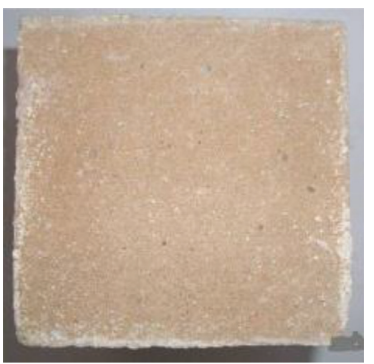

(g)

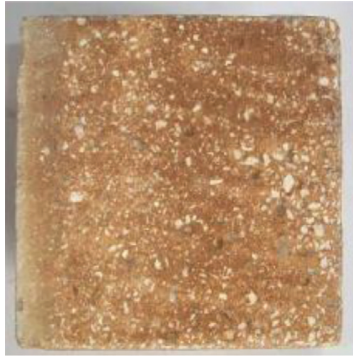

(d)

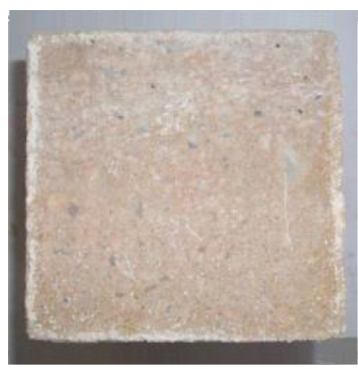

(h)

FigURE 3: Apparent characteristics of concrete subjected to sulfuric acid corrosion after 150 days. (a) $\mathrm{pH}=4.00, w / c=0.40$. (b) $\mathrm{pH}=3.70$, $w / c=0.50$. (c) $\mathrm{pH}=3.40, w / c=0.60$. (d) $\mathrm{pH}=3.10, w / c=0.70$. (e) $\mathrm{pH}=2.80, w / c=0.35$. (f) $\mathrm{pH}=2.50, w / c=0.45$. (g) $\mathrm{pH}=2.20, w / c=0.55$. (h) $\mathrm{pH}=2.00, w / c=0.65$.

since the nondissolved $\mathrm{CaSO}_{4}$ gradually deposited on concrete specimen surface, which blocked the surface pores and slowed down the corrosion reaction significantly.

4.2. Sulfuric Acid Corrosion Law for Concrete. According to the sulfuric acid corrosion tests for concrete, the acid consumption rate over time was measured as shown in Figure 5. The acid consumption rate of concrete in the early stage was relatively high, but it decreased rapidly and gradually stabilized with the corrosion reaction. The whole process consisted of two stages: the descending and stable periods. The cutoff point was approximately 800 hours. In addition, the lower the soaking solution's $\mathrm{pH}$ value was, the higher the initial acid consumption rate of concrete, leading to a greater sulfuric acid corrosion rate for concrete.

\section{Verification of the Sulfuric Acid Corrosion Model and Determination of an Apparent Diffusion Coefficient for $\mathrm{OH}^{-}$for Concrete}

5.1. Verification of the Sulfuric Acid Corrosion Model for Concrete. To clearly show the variation law of the acid consumption rate of concrete over time, the measured data

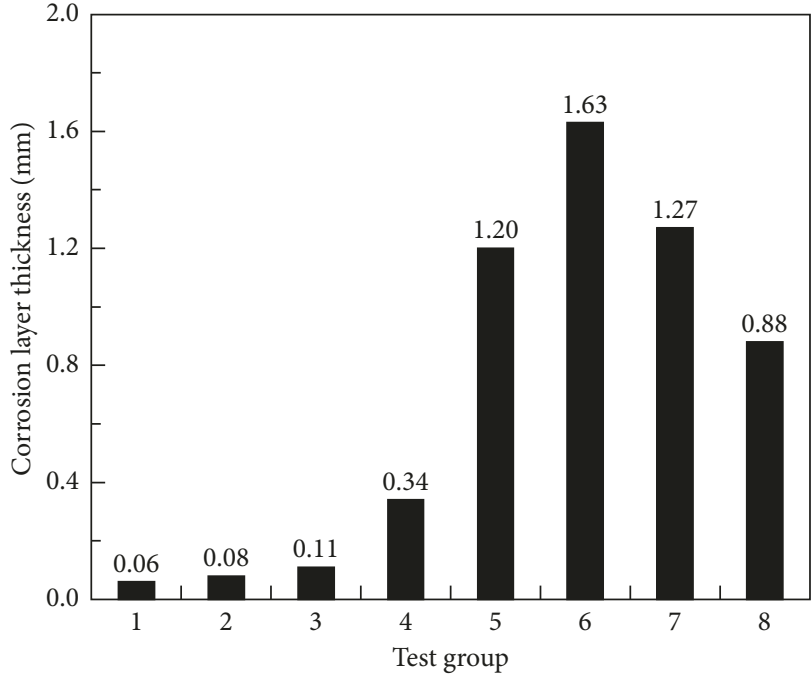

Figure 4: Corrosion layer thickness of concrete subjected to sulfuric acid corrosion after 150 days.

within 800 hours were fitted according to (9). The fitting parameters are seen in Table 5, and the fitting results are shown in Figure 6. Except for the last three groups of 


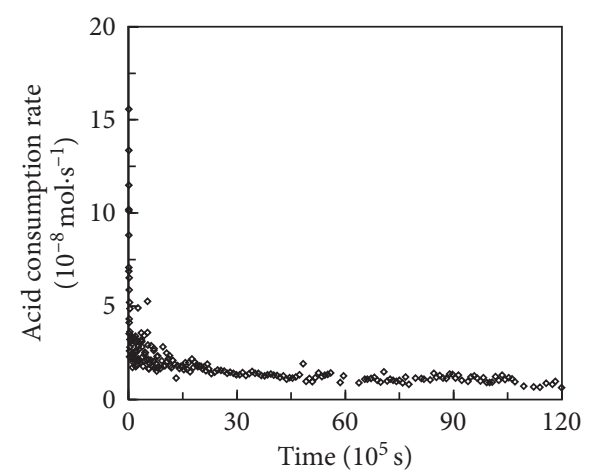

(a)

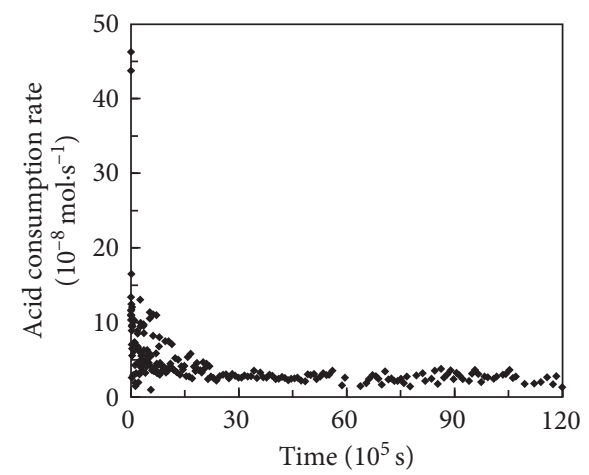

(c)

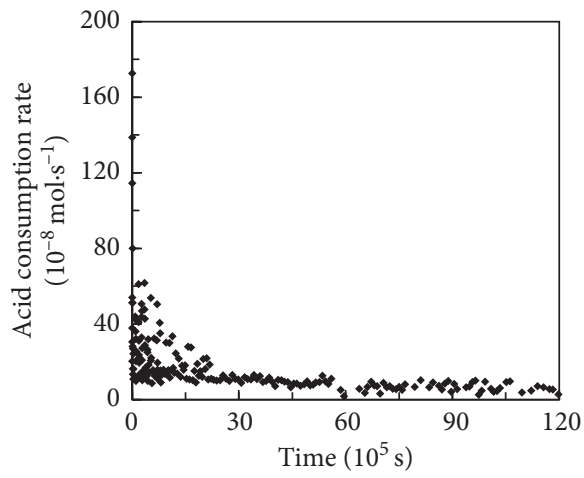

(e)

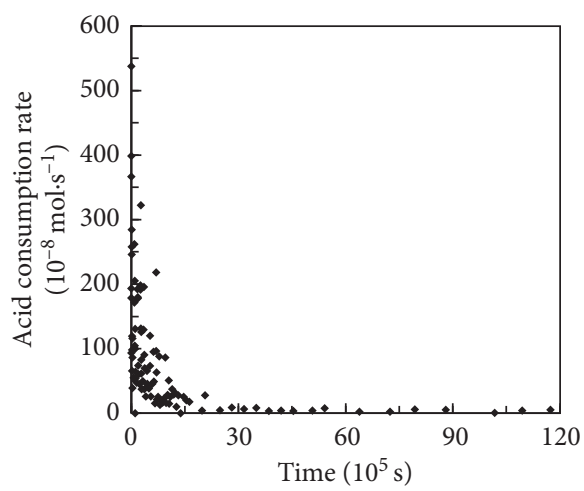

(g)

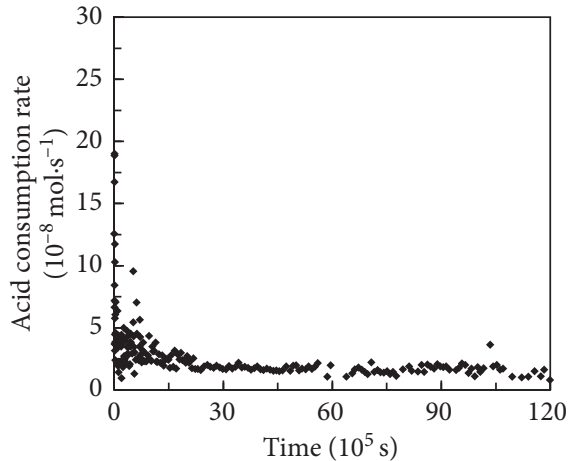

(b)

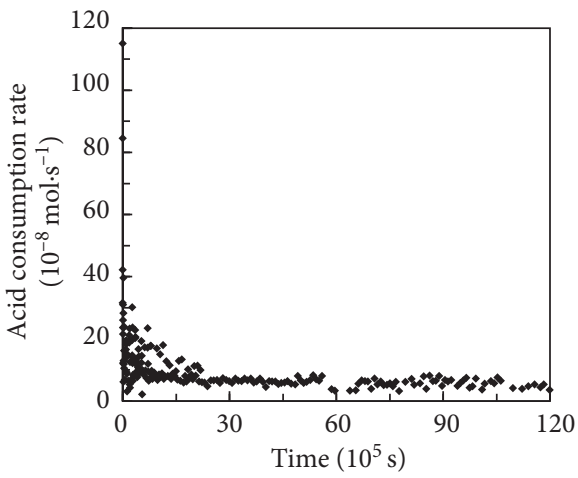

(d)

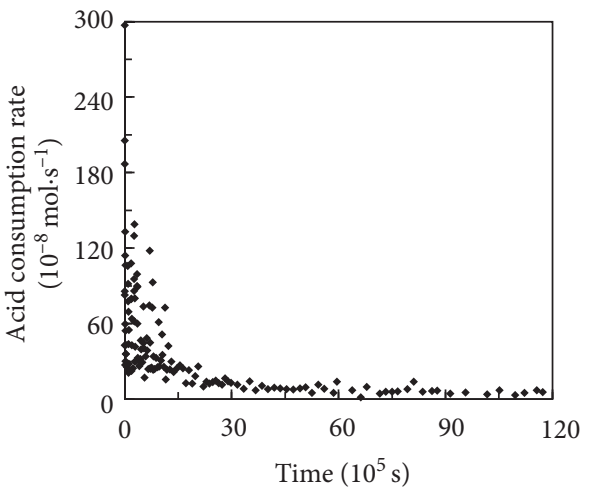

(f)

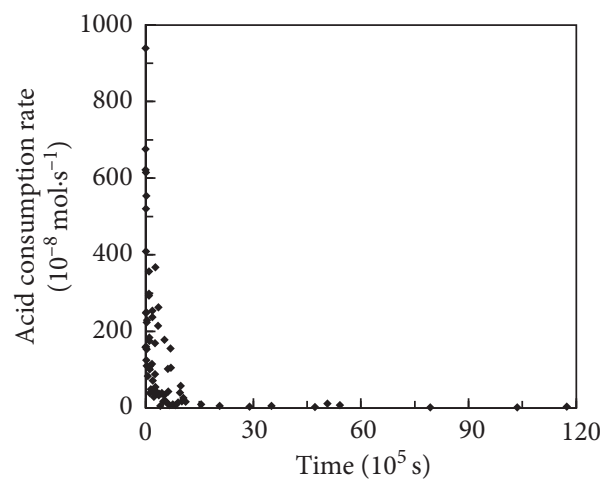

(h)

Figure 5: Relationship between the acid consumption rate and time. (a) $\mathrm{pH}=4.00, w / c=0.40$. (b) $\mathrm{pH}=3.70, w / c=0.50$. (c) $\mathrm{pH}=3.40$, $w / c=0.60$. (d) $\mathrm{pH}=3.10, w / c=0.70$. (e) $\mathrm{pH}=2.80, w / c=0.35$. (f) $\mathrm{pH}=2.50, w / c=0.45$. (g) $\mathrm{pH}=2.20, w / c=0.55$. (h) $\mathrm{pH}=2.00, w / c=0.65$. 
experimental data, (9) gave all test specimens a higher fitting degree. The theoretical model can reflect the change law affecting the acid consumption rate over time, thereby verifying the accuracy of the theoretical model. When the soaking time was relatively long (200 hours), the measured values of the acid consumption rate were slightly lower than fitted values, and this trend was more obvious with the decrease of $\mathrm{pH}$ value in the soaking solution. This phenomenon is related to the flocculent $\mathrm{CaSO}_{4}$ on the concrete surface, which is also called the boundary layer.

As the solubility of $\mathrm{CaSO}_{4}$ decreases with the decrease of soaking solution $\mathrm{pH}$ value, the boundary layer thickness increases with the decrease of $\mathrm{pH}$ value. The presence of the boundary layer results in a decrease in the reaction rate, which slows down the formation rate of $\mathrm{CaSO}_{4}$. At the same time, $\mathrm{CaSO}_{4}$ is constantly dissolving out of the concrete to reduce the $\mathrm{CaSO}_{4}$ concentration in the reaction boundary layer, resulting in the dissolution of the boundary layer, which increases the reaction rate. The deceleration or acceleration of the reaction rate caused by the formation or dissolution of the boundary layer will eventually reach a dynamic equilibrium.

5.2. Determination of an Apparent Diffusion Coefficient for $\mathrm{OH}$ for Concrete. Under a sulfuric acid corrosion environment, the dissolution of $\mathrm{Ca}(\mathrm{OH})_{2}$ in concrete results in the change of concrete pore structures, which further results in the change of concrete's apparent diffusion coefficient. However, the apparent diffusion coefficient for concrete is difficult to measure directly, and then the formula for calculating the apparent diffusion coefficient for $\mathrm{OH}^{-}$for concrete can be obtained by (9) as

$$
D_{\mathrm{OH}^{-}}=\frac{2 A^{2}}{B \cdot S^{2} \cdot C_{\mathrm{OH}^{-}}^{2} M \cdot N} .
$$

Choosing a shape function which can satisfy (5) yields

$$
\begin{aligned}
& \varphi(\theta)=(1-\theta)^{2}, \\
& \psi(\theta)=\theta^{2} .
\end{aligned}
$$

Substituting (11) in (7) gives

$$
\begin{aligned}
& M=\frac{1}{3}, \\
& N=2 .
\end{aligned}
$$

Substituting (12) in (10) yields

$$
D_{\mathrm{OH}^{-}}=\frac{3 A^{2}}{B \cdot S^{2} \cdot C_{\mathrm{OH}^{-}}} \text {. }
$$

The total area $S$ of the exposed surfaces of each group of concrete specimens was $0.03 \mathrm{~m}^{2}$, and the concentration of $\mathrm{OH}^{-}$ in the saturated $\mathrm{Ca}(\mathrm{OH})_{2}$ solution at $20^{\circ} \mathrm{C}$ was $0.045 \mathrm{~mol} \cdot \mathrm{L}^{-1}$; then, the apparent diffusion coefficients for $\mathrm{OH}^{-}$for concrete were obtained by using Table 5 and (13), as shown in Figure 7. When the soaking solution's $\mathrm{pH}$ value was more than 2.50 , the apparent diffusion coefficients for $\mathrm{OH}^{-}$for concrete increased slowly with the decrease of $\mathrm{pH}$ value and then increased rapidly with the further decrease of $\mathrm{pH}$ value.

5.3. Effects of Water-Cement Ratio, Soaking Solution's $p H$ Value, and Cement Proportion on the Apparent Diffusion Coefficient for $\mathrm{OH}^{-}$for Concrete. Because the relationship was not directly determined between the apparent diffusion coefficient for $\mathrm{OH}^{-}$for concrete and water-cement ratio, the soaking solution's $\mathrm{pH}$ value and cement proportion of $\mathrm{C} /(\mathrm{C}$ $+\mathrm{FA}+\mathrm{CA}$ ) required an analysis by ACE (alternating conditional expectation) regression [27] of nonparametric regression where $x_{1}, x_{2}, x_{3}$, and $y$ are water-cement ratio, soaking solution's $\mathrm{pH}$ value, cement proportion, and $\ln \left(D_{\mathrm{OH}^{-}} \times 10^{13}\right)$, respectively. Searching for the transformation relations of $\varphi_{1}\left(x_{1}\right), \varphi_{2}\left(x_{2}\right), \varphi_{3}\left(x_{3}\right)$, and $\theta(y)$ which can satisfy the following mapping relation between input parameters of $x_{1}, x_{2}, x_{3}$, and function of $y$ gave

$$
\theta(y)=\varphi_{1}\left(x_{1}\right)+\varphi_{2}\left(x_{2}\right)+\varphi_{3}\left(x_{3}\right) \text {. }
$$

Thus, the function $y$ was determined as

$$
y=\theta^{-1}\left[\varphi_{1}\left(x_{1}\right)+\varphi_{2}\left(x_{2}\right)+\varphi_{3}\left(x_{3}\right)\right] \text {. }
$$

The nonparametric regression analysis was performed using ACE. The fitting correlation coefficient was 0.9923, and the fitting effect was very good. Table 6 gives the values of each parameter before and after ACE regression, and (16) gives the mapping relations of $x_{1} \sim \varphi_{1}\left(x_{1}\right), x_{2} \sim \varphi_{2}\left(x_{2}\right)$, $x_{3} \sim \varphi_{3}\left(x_{3}\right)$, and $y \sim \theta(y)$ obtained using ACE. Figure 8 gives the relationship between the experimental and regression values for $y$, which is in good agreement with each other and has a positive proportion relationship. It can be seen from this that ACE has a very good practical value.

$$
\begin{aligned}
\varphi_{1}\left(x_{1}\right) & =3.4610 x_{1}-1.8173, \\
\varphi_{2}\left(x_{2}\right) & =-1.5847 x_{2}+4.6946, \\
\varphi_{3}\left(x_{3}\right) & =12.3549 x_{3}-2.3583, \\
\theta(y) & =0.3545 y-0.8446 .
\end{aligned}
$$

Combined with (14) to (16) as

$$
y=9.76 x_{1}-4.47 x_{2}+34.85 x_{3}+3.85
$$

Namely,

$$
\begin{aligned}
D_{\mathrm{OH}^{-}}= & 10^{-13} \times \exp \left(9.76 \frac{w}{c}-4.47 \mathrm{pH}\right. \\
& \left.+34.85 \frac{C}{C+\mathrm{FA}+\mathrm{CA}}+3.85\right) .
\end{aligned}
$$

Equation (18) showed that when the $\mathrm{pH}$ value decreased, water-cement ratio and cement proportion increased; thus, the corrosion degree of concrete subjected to sulfuric acid increased in severity.

\section{Conclusions}

With the decrease of soaking solution's $\mathrm{pH}$ value, the color of the exposed concrete specimen surface changed from gray 
TABLE 5: Fitting parameters.

\begin{tabular}{|c|c|c|c|c|c|c|c|c|}
\hline \multirow{2}{*}{ Parameter } & \multicolumn{8}{|c|}{ Test group } \\
\hline & 1 & 2 & 3 & 4 & 5 & 6 & 7 & 8 \\
\hline$A\left(10^{-8} \mathrm{~mol} \cdot \mathrm{s}^{-1}\right)$ & 2.1938 & 2.9611 & 5.1368 & 11.2014 & 20.6806 & 42.8333 & 74.4444 & 100.8056 \\
\hline$B\left(10^{-5} \mathrm{~s}^{-1}\right)$ & 8.2583 & 8.6528 & 13.1528 & 13.7472 & 14.4028 & 15.2111 & 12.2472 & 8.9056 \\
\hline$R^{2}$ & 0.9411 & 0.9520 & 0.8830 & 0.9157 & 0.8285 & 0.7160 & 0.5889 & 0.7013 \\
\hline
\end{tabular}

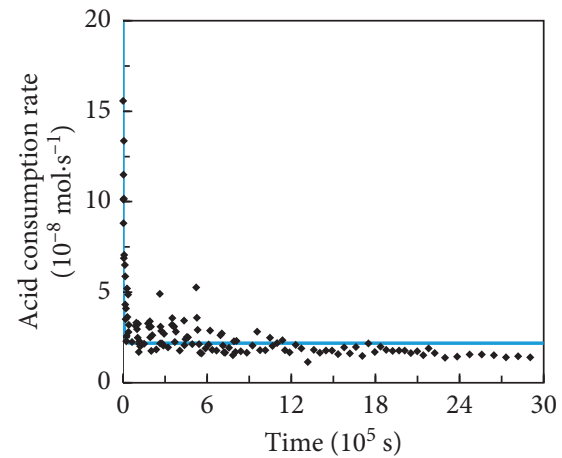

- Experimental values - Fitted values

(a)

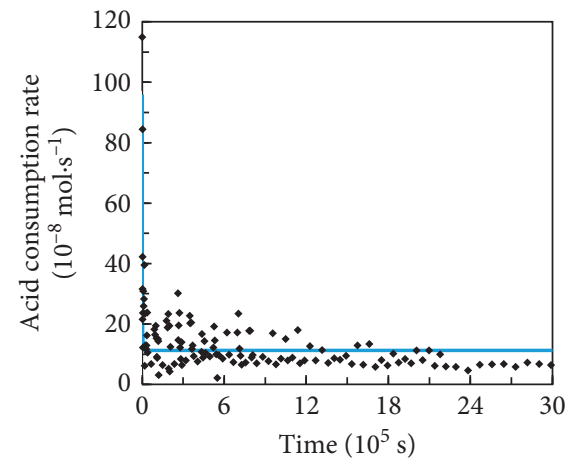

- Experimental values - Fitted values

(d)

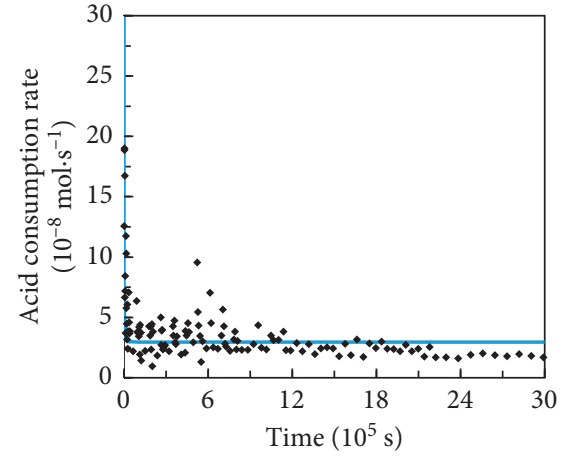

- Experimental values - Fitted values

(b)

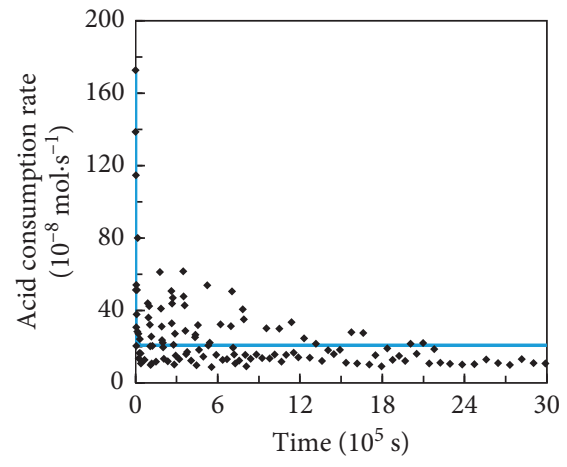

- Experimental values Fitted values

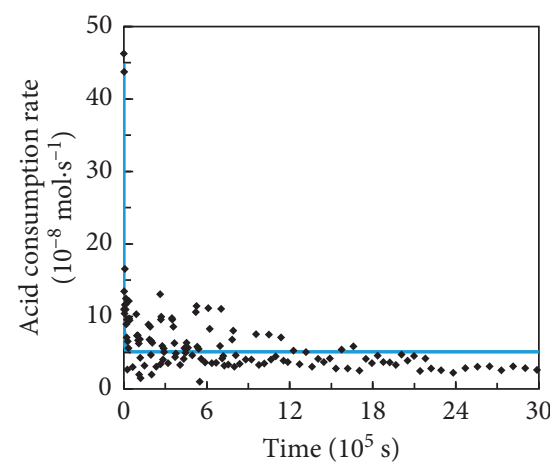

- Experimental values — Fitted values

(c)

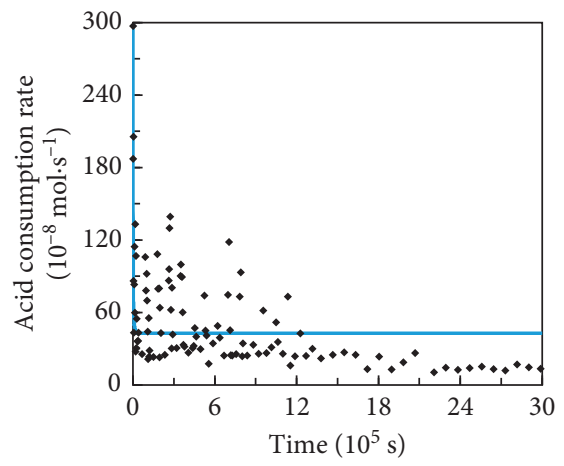

- Experimental values

— Fitted values

(f)

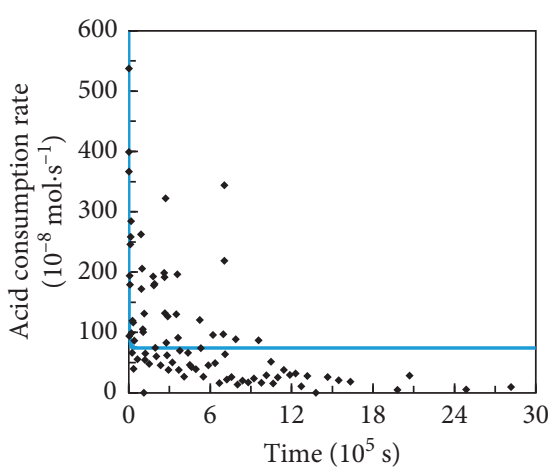

- Experimental values — Fitted values

(g)

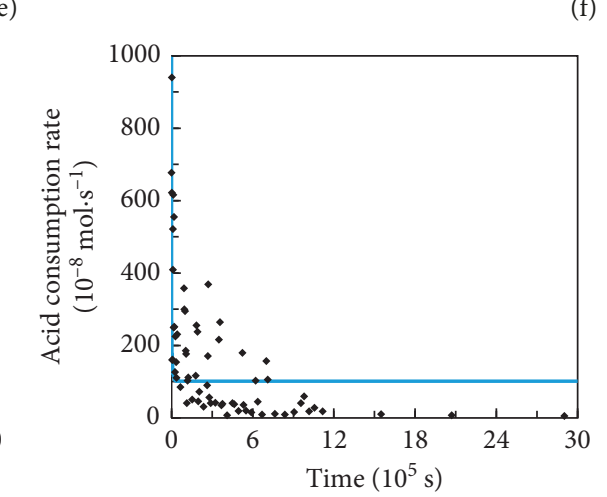

- Experimental values — Fitted values

(h)

FIGURE 6: Comparison of the experimental and fitted values of acid consumption rate. (a) $\mathrm{pH}=4.00, w / c=0.40 .(\mathrm{b}) \mathrm{pH}=3.70, w / c=0.50$. (c) $\mathrm{pH}=3.40, w / c=0.60$. (d) $\mathrm{pH}=3.10, w / c=0.70$. (e) $\mathrm{pH}=2.80, w / c=0.35$. (f) $\mathrm{pH}=2.50, w / c=0.45$. (g) $\mathrm{pH}=2.20, w / c=0.55$. (h) $\mathrm{pH}=2.00$, $w / c=0.65$. 


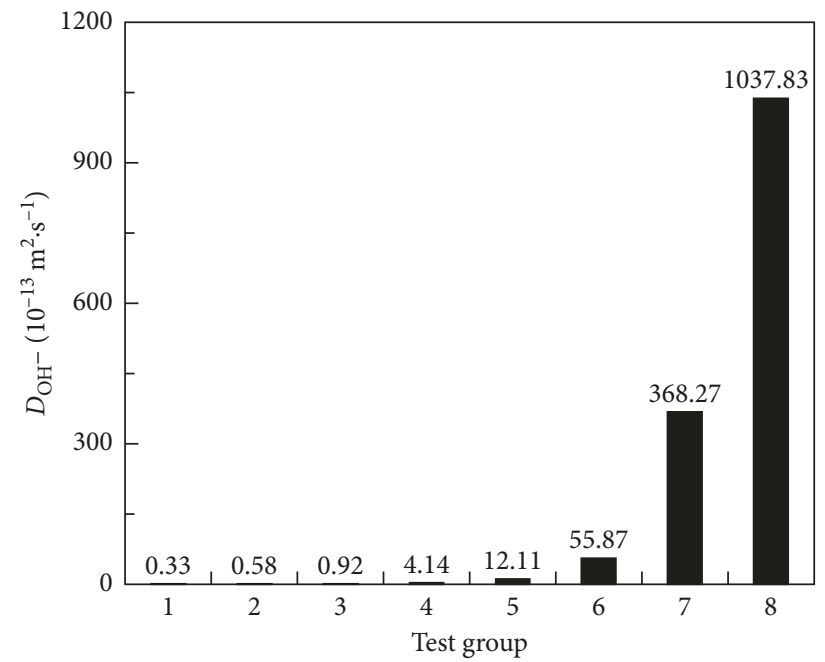

Figure 7: Apparent diffusion coefficient for $\mathrm{OH}^{-}$for concrete.

TABLE 6: Values of each parameter before and after ACE regression.

\begin{tabular}{lcccccccc}
\hline Test group & $x_{1}$ & $\varphi_{1}\left(x_{1}\right)$ & $x_{2}$ & $\varphi_{2}\left(x_{2}\right)$ & $x_{3}$ & $\varphi_{3}\left(x_{3}\right)$ & $y$ & $\theta(y)$ \\
\hline 1 & 0.40 & -0.4351 & 4.00 & -1.5887 & 0.2516 & 0.7424 & -1.0966 & -1.2613 \\
2 & 0.50 & -0.0811 & 3.70 & -1.1548 & 0.1966 & 0.0838 & -0.5447 & -1.0505 \\
3 & 0.60 & 0.2589 & 3.40 & -0.7209 & 0.1644 & -0.3253 & -0.0856 & -0.8750 \\
4 & 0.70 & 0.6036 & 3.10 & -0.2655 & 0.1414 & -0.6230 & 1.4195 & -0.3164 \\
5 & 0.35 & -0.6082 & 2.80 & 0.2116 & 0.2240 & 0.4054 & 2.4942 \\
6 & 0.45 & -0.2620 & 2.50 & 0.7093 & 0.2179 & 0.3361 & 4.0230 & 0.0668 \\
7 & 0.55 & 0.0926 & 2.20 & 1.2307 & 0.1791 & -0.1332 & 5.9088 & 1.2410 \\
8 & 0.65 & 0.4313 & 2.00 & 1.5783 & 0.1520 & -0.4864 & 6.9449 & 1.5903 \\
\hline
\end{tabular}

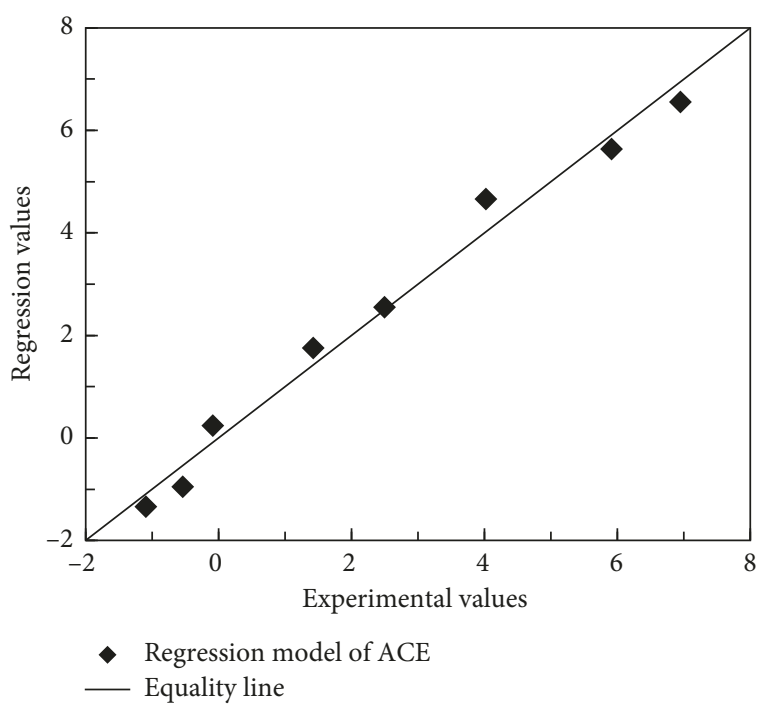

FIGURE 8: Comparison of the experimental and regression values for $y$.

to yellow and then to white. The corrosion layer thickness of the concrete specimen did not increase continuously with the decrease of $\mathrm{pH}$ value. When the soaking solution's $\mathrm{pH}$ value was 2.50 , the corrosion layer thickness reached the maximum value, which means the sulfuric acid corrosion degree of concrete was the most serious.

A sulfuric acid corrosion model for concrete was established based on the reaction boundary layer theory and was solved by applying the separation of variables. Then, a theoretical formula for the acid consumption rate of concrete was obtained. The sulfuric acid corrosion process of concrete can be divided into two stages, namely, the rapid corrosion stage and the stable corrosion stage. Because of the effect of the boundary layer, the measured acid consumption rate of concrete was slightly lower than the theoretical value when the soaking time was relatively long. Through the sulfuric acid corrosion tests for concrete, the accuracy of the sulfuric acid corrosion model for concrete was verified. This model can be used to predict the sulfuric acid corrosion mechanism for concrete in practical engineering and to provide the foundation for steel corrosion prediction.

The sulfuric acid corrosion tests for concrete were planned using uniform design. The apparent diffusion coefficient for $\mathrm{OH}^{-}$for concrete was chosen as the evaluation index for the sulfuric acid corrosion degree of concrete, and then the calculation formula was obtained through nonparametric regression. The results showed that the apparent diffusion coefficient for $\mathrm{OH}^{-}$for concrete increased when the $\mathrm{pH}$ value decreased and the water-cement ratio and 
cement proportion increased. The uniform design and nonparametric regression had a high efficiency in the experimental research and matched each other well, which was of great significance to this scientific research.

\section{Data Availability}

The data used to support the findings of this study are available from the corresponding author upon request.

\section{Conflicts of Interest}

The authors declare that they have no conflicts of interest.

\section{Acknowledgments}

This research was financially funded by the China Postdoctoral Science Foundation (2017M622789) and the National Natural Science Foundation of China (51078175).

\section{References}

[1] K. He, H. Yang, Z. B. Lu, F. F. Jia, E. P. Wang, and Q. X. Dong, "Effect of matrix modification on durability of cementitious composites in an acid rain environment," Journal of Wuhan University of Technology-Materials Science Edition, vol. 29, no. 3, pp. 498-503, 2014.

[2] M. P. Lavigne, A. Bertron, C. Botanch et al., "Innovative approach to simulating the biodeterioration of industrial cementitious products in sewer environment. Part II: validation on CAC and BFSC linings," Cement and Concrete Research, vol. 79, pp. 409-418, 2016.

[3] B. Huber, H. Hilbig, M. M. Mago, J. E. Drewes, and E. Müller, "Comparative analysis of biogenic and chemical sulfuric acid attack on hardened cement paste using laser ablation-ICPMS," Cement and Concrete Research, vol. 87, pp. 14-21, 2016.

[4] N. De Belie, J. Monteny, A. Beeldens, E. Vincke, D. Van Gemert, and W. Verstraete, "Experimental research and prediction of the effect of chemical and biogenic sulfuric acid on different types of commercially produced concrete sewer pipes," Cement and Concrete Research, vol. 34, no. 12, pp. 2223-2236, 2004.

[5] P. K. Mehta, "Durability of concrete-fifty years of progress?," in Proceeding of the 2nd International Conference on Concrete Durability ACI SP126-01, pp. 1-32, Sapporo, Japan, 1991.

[6] Y. Yang, T. Ji, X. J. Lin, C. Y. Chen, and Z. X. Yang, "Biogenic sulfuric acid corrosion resistance of new artificial reef concrete," Construction and Building Materials, vol. 158, pp. 33-41, 2018.

[7] L. Gu, P. Visintin, and T. Bennett, "Evaluation of accelerated degradation test methods for cementitious composites subject to sulfuric acid attack, application to conventional and alkaliactivated concretes," Cement and Concrete Composites, vol. 87, pp. 187-204, 2018.

[8] X. Li, Y. X. Lin, K. Lin, and T. Ji, "Study on the degradation mechanism of sulphoaluminate cement sea sand concrete eroded by biological sulfuric acid," Construction and Building Materials, vol. 157, pp. 331-336, 2017.

[9] E. Hewayde, M. Nehdi, E. Allouche, and G. Nakhla, "Effect of mixture design parameters and wetting-drying cycles on resistance of concrete to sulfuric acid attack," Journal of Materials in Civil Engineering, vol. 19, no. 2, pp. 155-163, 2007.

[10] Y. F. Fan, Z. Q. Hu, H. Y. Luan, D. W. Wang, and A. Chen, "A study of deterioration of reinforced concrete beams under various forms of simulated acid rain attack in the laboratory," Structural Engineering and Mechanics, vol. 52, no. 1, pp. 35-49, 2014.

[11] A. Grandclerc, P. Dangla, and M. Gueguen-Minerbe, "Modelling of the sulfuric acid attack on different types of cementitious materials," Cement and Concrete Research, vol. 105, pp. 126-133, 2018.

[12] J. Hill, E. A. Byars, J. H. Sharp, C. J. Lynsdale, J. C. Cripps, and Q. Zhou, "An experimental study of combined acid and sulfate attack of concrete," Cement and Concrete Composites, vol. 25, no. 8, pp. 997-1003, 2003.

[13] Z. T. Chang, X. J. Song, R. Munn, and M. Marosszeky, "Using limestone aggregates and different cements for enhancing resistance of concrete to sulphuric acid attack," Cement and Concrete Research, vol. 35, no. 8, pp. 1486-1494, 2006.

[14] H. G. Min, W. P. Zhang, and X. L. Gu, "Effects of load damage on moisture transport and relative humidity response in concrete," Construction and Building Materials, vol. 169, pp. 59-68, 2018.

[15] H. G. Min, W. P. Zhang, X. L. Gu, and R. Cerný, "Coupled heat and moisture transport in damaged concrete under an atmospheric environment," Construction and Building Materials, vol. 143, pp. 607-620, 2017.

[16] W. P. Zhang, H. G. Min, and X. L. Gu, “Temperature response and moisture transport in damaged concrete under an atmospheric environment," Construction and Building Materials, vol. 123, pp. 290-299, 2016.

[17] W. P. Zhang, H. G. Min, X. L. Gu, Y. Xi, and Y. S. Xing, "Mesoscale model for thermal conductivity of concrete," Construction and Building Materials, vol. 98, pp. 8-16, 2015.

[18] S. Mirvalad and M. Nokken, "Studying thaumasite sulfate attack using compressive strength and ultrasonic pulse velocity," Materials and Structures, vol. 49, no. 10, pp. 41314146, 2016.

[19] M. O. Yusuf, "Performance of slag blended alkaline activated palm oil fuel ash mortar in sulfate environments," Construction and Building Materials, vol. 98, pp. 417-424, 2015.

[20] S. D. Xie, L. Qi, and D. Zhou, "Investigation of the effects of acid rain on the deterioration of cement concrete using accelerated tests established in laboratory," Atmospheric Environment, vol. 38, no. 27, pp. 4457-4466, 2004.

[21] M. Böhm, J. Devinny, F. Jahani, and G. Rosen, "On a movingboundary system modeling corrosion in sewer pipes," Applied Mathematics and Computation, vol. 92, no. 2-3, pp. 247-269, 1998.

[22] M. Böhm, J. Devinny, F. Jahani, F. B. Mansfeld, I. G. Rosen, and C. Wang, "A moving boundary diffusion model for the corrosion of concrete wastewater systems: simulation and experimental validation," in Proceedings of the American Control Conference, pp. 1739-1743, San Diego, CA, USA, 1999.

[23] F. Jahani, J. Devinny, F. Mansfeld, and I. G. Rosen, "Investigations of sulfuric acid corrosion of concrete. I: modeling and chemical observations," Journal of Environmental Engineering, vol. 127, no. 7, pp. 572-579, 2001.

[24] Z. G. Song, X. S. Zhang, and H. G. Min, "Concentration boundary layer model of mortar corrosion by sulfuric acid," Journal of Wuhan University of Technology-Materials Science Edition, vol. 26, no. 3, pp. 527-532, 2011.

[25] K. T. Fang, Uniform Design and Uniform Design Table, Science Press, Beijing, China, 1994, in Chinese.

[26] K. T. Fang and C. X. Ma, Orthogonal and Uniform Design of Experiments, Science Press, Beijing, China, 2001, in Chinese.

[27] A. M. Hasofer and J. Qu, "Response surface modelling of monte carlo fire data," Fire Safety Journal, vol. 37, no. 8, pp. 772-784, 2002. 


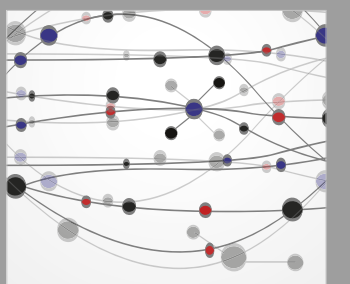

The Scientific World Journal
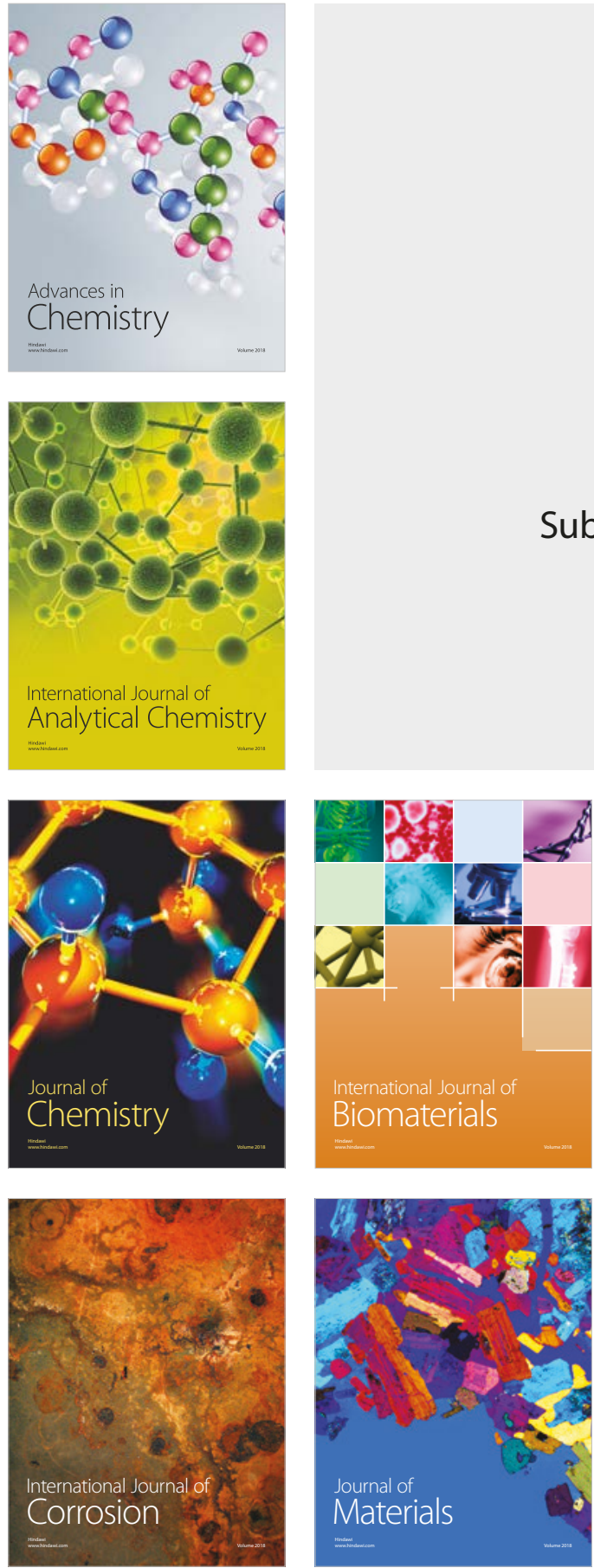

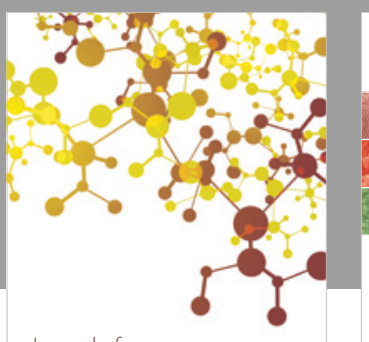

Journal of

Applied Chemistry
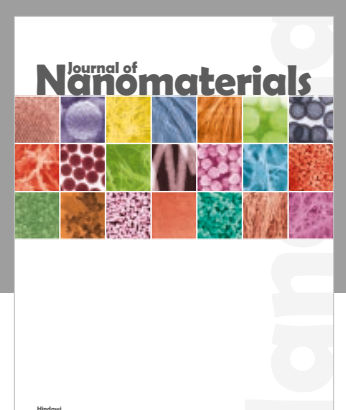

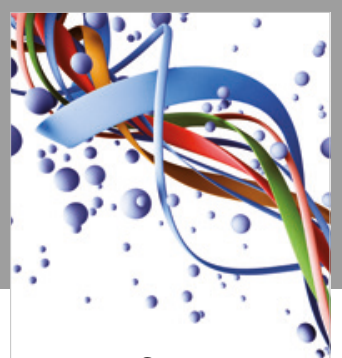

Scientifica

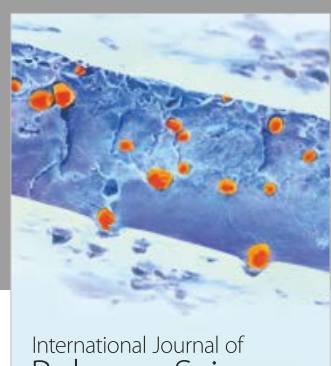

Polymer Science

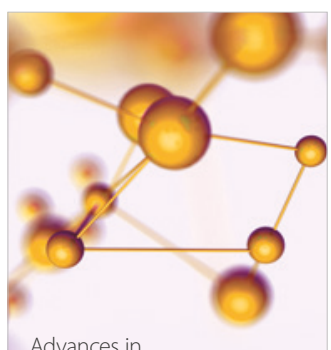

Physical Chemistry
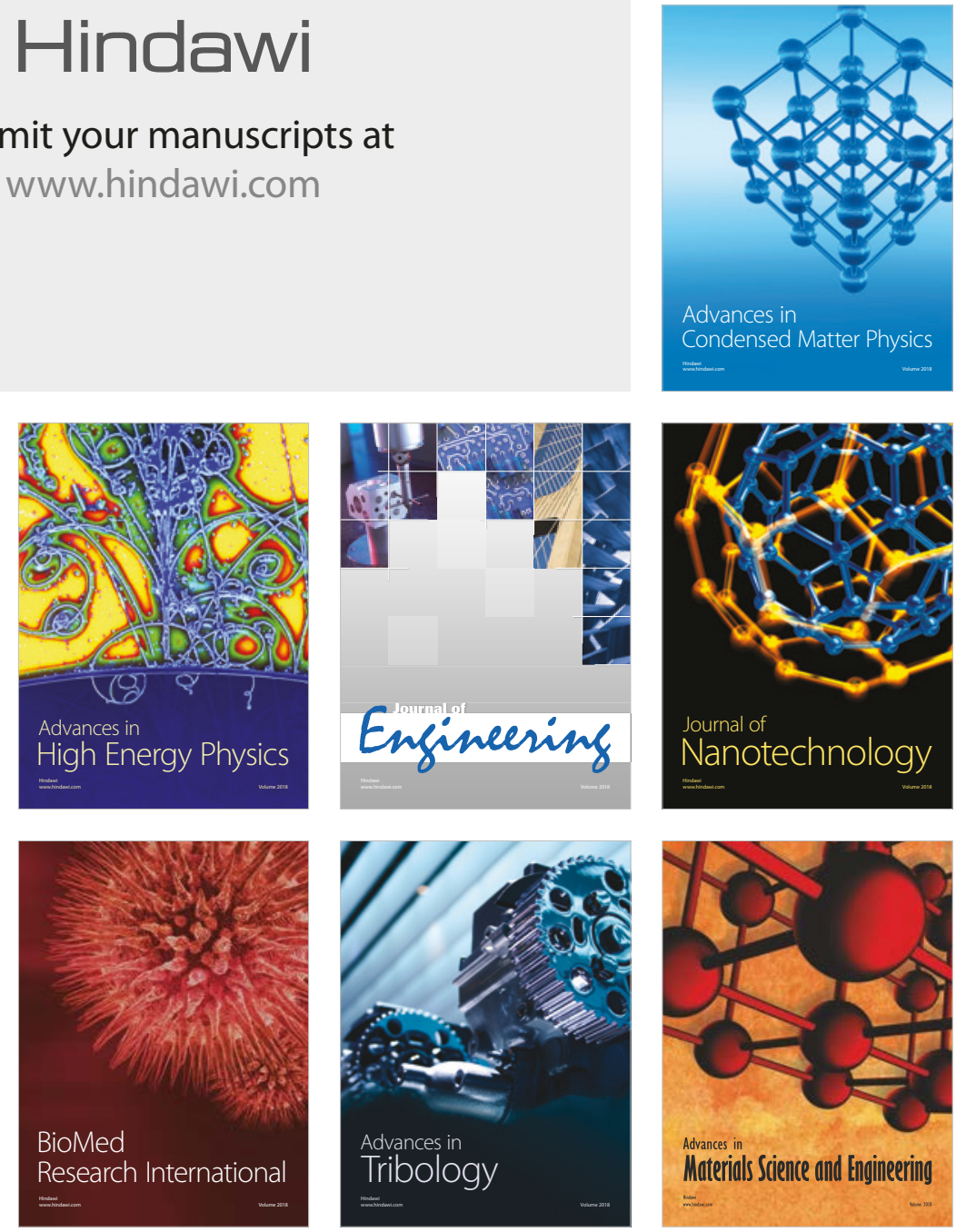